ORIGINAL ARTICLE

\title{
Accuracy of task recall for epidemiological exposure assessment to construction noise
}

\author{
C K Reeb-Whitaker, N S Seixas, L Sheppard, R Neitzel
}

Occup Environ Med 2004;61:135-142. doi: 10.1136/oem.2002.000489

See end of article for authors' affiliations

Correspondence to: C Reeb-Whitaker, Washington Department of Labor and Industries, Safety and Health Assessment and Research for Prevention (SHARP)

Program, PO Box 44330, Olympia, Washington 98504, USA;

whca235@Lni.wa.gov

Accepted 26 March 2003

\begin{abstract}
Aims: To validate the accuracy of construction worker recall of task and environment based information; and to evaluate the effect of task recall on estimates of noise exposure.

Methods: A cohort of 25 construction workers recorded tasks daily and had dosimetry measurements weekly for six weeks. Worker recall of tasks reported on the daily activity cards was validated with research observations and compared directly to task recall at a six month interview.

Results: The mean $\mathrm{L}_{E Q}$ noise exposure level $(\mathrm{dBA})$ from dosimeter measurements was $89.9(n=61)$ and $83.3(n=47)$ for carpenters and electricians, respectively. The percentage time at tasks reported during the interview was compared to that calculated from daily activity cards; only $2 / 22$ tasks were different at the nominal $5 \%$ significance level. The accuracy, based on bias and precision, of percentage time reported for tasks from the interview was 53-100\% (median 91\%). For carpenters, the difference in noise estimates derived from activity cards (mean $91.9 \mathrm{dBA}$ ) was not different from those derived from the questionnaire (mean $91.7 \mathrm{dBA}$ ). This trend held for electricians as well. For all subjects, noise estimates derived from the activity card and the questionnaire were strongly correlated with dosimetry measurements. The average difference between the noise estimate derived from the questionnaire and dosimetry measurements was $2.0 \mathrm{dBA}$, and was independent of the actual exposure level.

Conclusions: Six months after tasks were performed, construction workers were able to accurately recall the percentage time they spent at various tasks. Estimates of noise exposure based on long term recall (questionnaire) were no different from estimates derived from daily activity cards and were strongly correlated with dosimetry measurements, overestimating the level on average by $2.0 \mathrm{dBA}$.
\end{abstract}

l: is well documented that construction workers are exposed to harmful levels of noise. Noise measurements (eight hour time weighted average (TWA)) for construction workers range from 74 to 108 decibels (dBA) ${ }^{1-5}$ The number of construction workers exposed to daily noise levels above 85 dBA was estimated in the early 1980s at 421 000-513000 workers. ${ }^{67}$ More recent estimates of the number of construction workers exposed to noise are lacking. A 1998 risk assessment on occupational noise conducted by the National Institutes of Occupational Safety and Health (NIOSH) indicated that a 40 year lifetime exposure to 85 or 90 decibels (dBA) is associated with an excess risk of developing occupational hearing loss of $8 \%$ and $25 \%$, respectively. ${ }^{7}$ In addition to hearing loss, chronic exposure to noise may affect the cardiovascular system, ${ }^{89}$ compromise balance, ${ }^{10}$ interfere with communication, ${ }^{11}$ and contribute to social and psychological problems. ${ }^{12}$

Preventing hearing loss in construction is particularly challenging because the workers are highly mobile, and generally do not retain steady employment with any given contractor. It is difficult therefore to ensure that individuals receive formalised education on hearing loss or are enrolled in an effective hearing conservation programme. Less regulatory protection is afforded to the construction industry than in general industry, and routine audiometric testing that might inspire a worker to use hearing protection is typically not available to transient workers like those found in construction.

Exposure assessment for epidemiology of construction risks is similarly challenging because of the dynamic nature of the work. Attributing exposure by task may reveal more useful exposure information than the traditional approach using job title or exposure group alone. Such a task based approach can also be used to identify activities that result in over-exposure and to evaluate control measures. ${ }^{13}$
For these reasons, recent studies of health issues in the construction industry have adopted a task based exposure assessment strategy. Efforts to characterise highway construction have been undertaken using task based sampling methods for workers involved in the central artery/tunnel construction project in Boston, Massachusetts. ${ }^{14}{ }^{15}$ In the evaluation of exposure to metal fumes, Susi et al described a task based exposure assessment model (T-BEAM) that was applied to boilermakers, pipe fitters, and ironworkers. ${ }^{16}$ In the residential construction sector, Methner et al conducted a "range finding" study in which they assessed chemical exposure during 19 different tasks performed by 12 different trades. ${ }^{17}$ Other studies have documented task based noise measurements for carpenters, labourers, ironworkers, and operating engineers. ${ }^{518} 19$ The task based exposure assessment strategy used in these studies included information not only on the task being performed, but also on additional exposure determinants such as the work environment, duration of work, tools used, adjacent workers, and other pertinent factors associated with the exposure.

Task based exposure assessment can be very useful in epidemiological studies; however, such an approach requires that subjects can accurately recall their work tasks. Education can be a determinant in valid recall regarding the start date of a job, ${ }^{20}$ and the validity of self report data has been found to decline with the precision required by the data. ${ }^{21}$ Education, social class, and age (for normal working age individuals) do not have an effect on a subject's ability to recall very basic information. ${ }^{20}{ }^{22}$ While published studies have addressed lifelong recall of work histories, few have assessed the accuracy of recall of detailed work characteristics such as the time spent in specific exposure related work tasks.

The goal of the study presented here was to validate the accuracy of construction worker recall of task and 


\section{Main messages}

- Task based exposure assessment methods require accurate recall by study subjects. Construction apprentices were able to recall the percentage time they spent at various tasks with accuracy sufficient for exposure assessment.

- Estimates of noise exposure, based on subject recall, were strongly correlated with dosimetry measurements taken during the recall period.

environment based information. In addition to validating reporting accuracy, the effect of task recall on estimates of noise exposure was evaluated.

\section{METHODS}

The study was conducted at four different commercial building sites in the Seattle, Washington area and consisted of a six week (July-August 2000) field based assessment with a follow up interview conducted six months later. The field assessment included daily recording of tasks performed by each subject, and weekly measurement of noise exposure and observation of work tasks by research personnel. A total of 25 apprentices on the four sites were informed about the study and agreed to participate. The subjects included 11 carpenters, nine electricians, two sheet metal workers, and one each of operating engineers, sprinkler fitters, and labourers. Because there were so few subjects in the latter four trades, these trades were grouped together as "other" trades.

Two sites (A and D) included four and nine subjects, respectively. These sites were in the structural phase, which includes foundation slab pour, steel/column erection, and floor/roof concrete pours. Site B had six subjects and was in the site preparation phase, which includes grading, tower crane erection, and structural erection. Site $\mathrm{C}$ had six subjects who were engaged in finishing operations.

All subjects wore noise dosimeters (Quest model Q-300, Oconomowoc, WI) and were observed from approximately $730 \mathrm{am}$ to $330 \mathrm{pm}$ one day per week. Dosimeters were clipped to the tool belt and the microphone was placed either on their hard hat or on their collar, within $10 \mathrm{~cm}$ of their ear and on the same side of the body as their dominant hand. Noise in this study was measured in A-weighted decibels, using the OSHA metric ( 5 decibel $(\mathrm{dB})$ exchange rate) and the NIOSH metric ( $3 \mathrm{~dB}$ exchange rate). The exchange rate is the number of $\mathrm{dB}$ required to halve or double the duration of acceptable exposure. Only the results based on the NIOSH metric are presented here because this metric best describes risk of noise induced hearing loss. ${ }^{7}$

Seventeen subjects were randomly selected to complete one activity card per day for six weeks; the remaining eight subjects were asked not to complete activity cards. Those who did not complete activity cards served as a control group for evaluating the effect completing the card might have had on recall. The trade specific activity cards were developed during a previous study. ${ }^{18}$ The front of each card listed tasks and tools common to a specific trade. For the carpenter, electrician, and sheet metal trades, the total number of different tasks listed on the activity card ranged from 8 to 11 and the number of tools ranged from 9 to 11 . The operating engineer card had a total of 14 tasks and two tools, while the labourer card listed 12 tasks and seven tools. The category "other" allowed subjects to write in additional tasks or tools that may not have been listed. Adjacent to the task/tool list was a time line running from 5 am to $5 \mathrm{pm}$. Each subject was instructed to indicate the time of day a given task was

\section{Policy implications}

- That construction apprentices could accurately recall their tasks in this study is relevant to future task based epidemiological studies in the construction industry.

performed or tool was used, with a 15 minute time resolution. The back of the card contained another time line running from 5 am to $5 \mathrm{pm}$, and subjects were asked to indicate time spent wearing hearing protection, type of work area (outside/inside/partial enclosure), and number of workers nearby ( 3 or fewer/4 or more). Subjects were encouraged to carry the activity card with them throughout the day to maximise their reporting accuracy.

Subjects were observed and had dosimetry measurements once per week on a randomly selected day. Research observations were conducted on each subject multiple times per shift for a period of 10-15 minutes. With the ratio of researchers to subjects that we had per site, it was a goal to watch each subject at least once per hour. Subjects were not observed during breaks or lunch. Research staff recorded observations on a tally sheet containing the same categories as the trade specific activity cards. Tasks were mutually exclusive, and if more than one task was observed during an observation period, the dominant task was reported. Tools, however, were not mutually exclusive, and a list of all tools used was recorded. For analysis, the unit of time used to compare dosimetry, activity card information, and researcher observation was one minute intervals. This was dictated by the fact that the dosimeters gave one reading per minute.

Approximately six months after the intensive task card and observation period, 23 subjects completed the work history questionnaire. Two subjects did not complete the interview: one subject could not be located and the other subject was located but did not complete the questionnaire. The interview was conducted over the telephone, with copies of the questionnaire mailed to the subject's home in advance. The questionnaire was trade specific and contained the same list of tasks and environmental details present on the activity cards. For example, carpenters were given a list of 10 tasks common to that trade and asked to estimate the time they spent at any given task during July and August 2000. The total time spent on all possible tasks was always equal to $100 \%$ time.

The variability in noise exposure between all workers and by trade was calculated from the variance components of an analysis of variance (ANOVA) and the methods outlined in Boleij. ${ }^{23}$ The ratio of the 97.5th and 2.5th centiles of the between-worker distribution was calculated to describe the range of exposures experienced between workers from day to day.

The agreement of subject self report and researcher observation of task, environment, and number of nearby workers was tested with the kappa statistic. The kappa is a measure of agreement scaled from 0 to 1 , with 0 being the agreement that might occur by chance, and 1 being perfect agreement. Qualitative descriptions for the values between 0 and 1 have been proposed as: slight $(0.00-0.20)$, fair $(0.21-$ $0.40)$, moderate $(0.41-0.60)$, substantial (0.61-0.80), and almost perfect $(0.81-1.00) .{ }^{24} \chi^{2}$ analysis was used to compare self reported use of hearing protection with researcher observation. If data were missing from either the activity card or the research observation sheet, the missing data were included but coded as "missing".

The mean percentage time at a task was calculated from the activity cards and compared to the percentage time 
reported on the questionnaire using paired $t$ tests. In addition, the bias (mean $\left(\mathrm{X}_{\mathrm{q}}-\mathrm{X}_{\mathrm{ac}}\right)$ ), and precision (SD of $X_{\mathrm{q}}-\mathrm{X}_{\mathrm{ac}}$ ), where $\mathrm{X}_{\mathrm{q}}$ and $\mathrm{X}_{\mathrm{ac}}$ are the time reported at a specific task on the questionnaire (q) or the activity card (ac) were calculated.$^{25}$ These measures were combined to provide a summary measure of accuracy $=\left(100-\sqrt{\text { bias }^{2}+\text { precision }^{2}}\right) \cdot{ }^{25}$ Confidence intervals (95\%) were provided for the bias estimates.

Noise estimates were calculated using the percentage time at task reported on both the activity card and the questionnaire. Mean differences in the estimates derived from the activity card, the questionnaire, and dosimetry were compared using paired analysis and summary confidence intervals. Simple linear regression models were constructed to investigate the relation between the dosimetry measurements and either the activity card based estimates or the questionnaire based estimates.

The taskbased estimates of noise exposure, were made using:

$$
L_{E Q, i}=q^{*} \log _{10}\left[\sum_{t=1}^{T} p_{i, t}\left(\frac{\sum_{m=1}^{M}\left(10^{\frac{L m}{q}}\right)}{M}\right)_{t}\right]
$$

Where:

$L_{E Q, i}=$ noise estimate for subject $i$, on a given day

$q=$ exchange rate $(3 \mathrm{dBA}) / \log (2)=10$

$T=$ total number of tasks performed by a given worker

$p_{i, t}=$ percentage time reported at a given task $(t)$ by each worker $(i)$

$L_{m}=$ noise level logged at one minute interval by dosimeter $M=$ total number of minutes all subjects spent at a given task, $t$

Noise estimates were made using $p_{i, t}$ estimated from the individual's activity card or recall questionnaire, and compared using paired $t$ tests.

\section{RESULTS}

Table 1 describes the number of subjects that participated in various components of the study. Of the 25 subjects that were observed, 17 subjects were asked to complete daily self report activity cards and all complied, yielding a total of 389 daily activity cards. Twenty three subjects completed the work history questionnaire. Three subjects were female; the average age of all subjects was 30 (8) years. At the onset of the study, subjects had completed an average of 6 (16) months apprentice work in their given trade.

A total of 130 subject/days of noise measurements were completed, with an average work shift noise level ranging from 78.5 (2.1) dBA for sprinkler fitters to 90.6 (1.5) dBA for operating engineers (see table 2 ). Carpenters had an average level of 89.9 (4.1) dBA and electricians averaged 83.3 (3.8) dBA. Overall, $60 \%$ of the samples exceeded $85 \mathrm{dBA}$, the NIOSH recommended exposure limit (REL). Operating engineers, carpenters, and sheet metal workers had the greatest percentage of samples that exceeded the permissible exposure limit.

Table 3 shows the variability between and within workers for dosimetry measurements. For all subjects combined the within and between worker variances were comparable. For carpenters, the variability in dosimetry measurements between workers was very low with $a_{B} \sigma^{2}$ of 0.3 indicating that they had similar noise exposure day-to-day. In contrast, electricians had somewhat higher day-to-day variability in dosimetry measurements between workers with $\mathrm{a}_{\mathrm{B}} \sigma^{2}$ of 3.2, suggesting that electricians vary more in their individual exposures. Not surprisingly, the "other trades" encompasses several different trades, and the variability in noise estimates between workers was the highest at 5.3. The range of exposures, ${ }_{\mathrm{B}} \mathrm{R}_{95}$, is very small for carpenters (1.0) and much larger for electricians (12.5).

Daily activity cards were completed for an average of $88 \%$ time of the six week field assessment. During the field assessment, subjects were observed for six days each, for approximately $11 \%$ of their work day. Table 4 shows the agreement (kappa) between daily activity cards and research observations. For tasks reported, the agreement for all subjects with research observation was substantial $(0.67$ $(0.1))$. Carpenters and electricians had similar task reporting concordance $(0.64(0.1))$ and the concordance for the "other" trades was moderate $(0.51(0.1))$. Information regarding the environment was reported with a higher concordance than task for all subjects $(0.70(0.1))$. Carpenters and electricians both had concordance values that are considered substantial (0.71 and 0.67, respectively), while the "other" trade was moderate $(0.51)$. The reporting of number of nearby workers was considered fair for all subjects combined $(0.24(0.1))$. Carpenters reported the number of workers with poor concordance $(0.13(0.1))$; workers from the "other" trades did better $(0.49(0.3))$.

The variability of tasks was characterised by determining the average number of tasks reported per day. The number of tasks reported per day ranged from 1 to 4 for all subjects and the mean number of tasks reported per day was 2.5 for all subjects, with little variability by trade.

Twenty three of 25 subjects completed the work history questionnaire six months after the initial assessment. The questionnaire was specific to activities that took place during the reporting and observation period of July and August 2000. In addition to describing their work history subjects were asked about things that may affect their recall. There were a total of 28 work weeks between 1 July and the week the questionnaire was administered; subjects reported that they worked an average of 23.6 (4.8) weeks during this period. Electricians reported working the greatest number of weeks (27) while the carpenters reported working the fewest weeks (21). Construction workers often change job sites and the average number of different sites worked at since the assessment was $1.8(1.2)$.

Tables 5 and 6 compare the average percent time reported on the daily activity cards with that reported on the questionnaire. Overall, the accuracy for reporting task

\begin{tabular}{llllll} 
Table 1 & Subject participation \\
\hline \multicolumn{7}{l}{$\begin{array}{l}\text { No. of subjects } \\
\text { observed }\end{array}$} & $\begin{array}{l}\text { Observation/ } \\
\text { dosimetry days }\end{array}$ & $\begin{array}{l}\text { No. of subjects } \\
\text { completing daily } \\
\text { activity cards }\end{array}$ & $\begin{array}{l}\text { Activity card } \\
\text { days }\end{array}$ & $\begin{array}{l}\text { No. of subjects } \\
\text { completing } \\
\text { interview }\end{array}$ \\
\hline All subjects & 25 & 130 & 17 & 389 & 23 \\
Carpenter & 11 & 60 & 8 & 196 & 10 \\
Electrician & 9 & 47 & 5 & 118 & 8 \\
Other trades* & 5 & 23 & 4 & 75 & 5 \\
\hline *Other trades includes labourer (1), sheet metal worker (2), sprinkler fitter (1), and operating engineer (1).
\end{tabular}


Table 2 Mean decibel measured $\left(L_{E Q}\right)$ during shifts

\begin{tabular}{lcccc}
\hline & No. of subjects & DBA, mean (SD) & $\begin{array}{l}\text { \% of samples }>\mathbf{8 5} \\
\text { dBA }\end{array}$ & $\begin{array}{l}\text { Sample time, } \\
\text { minutes, mean (SD) }\end{array}$ \\
\hline All subjects & 130 & $86.5(5.2)$ & 60 & $460(48)$ \\
Carpenter & 61 & $89.9(4.1)$ & 87 & $464(49)$ \\
Electrician & 47 & $83.3(3.8)$ & 32 & $462(48)$ \\
Other trades* & 22 & $84.1(5.2)$ & 2 & $448(46)$ \\
Labourer & 4 & $84.2(1.8)$ & 25 & $440(18)$ \\
Sheet metal worker & 8 & $85.0(4.8)$ & 63 & $435(30)$ \\
Operating engineer & 4 & $90.6(1.5)$ & 100 & $523(14)$ \\
Sprinkler fitter & 6 & $78.5(2.1)$ & 0 & $421(41)$ \\
\hline \multirow{2}{*}{ *Other trades includes labourer, sheet metal worker, operating engineer, and sprinkler fitter. }
\end{tabular}

(table 5) was better than the accuracy for reporting the tools, number of workers, or the work environment (table 6).

In general, subjects recalled task time percentages on the questionnaire no differently than what they had reported on daily activity cards. Time spent at two of the 22 tasks was reported significantly differently. The task break/rest/cleanup (all subjects) was overestimated on the questionnaire and building gang forms (carpenters) was underestimated on the questionnaire compared to the activity cards. The percentage time spent at both of these tasks was reported with significant difference at a nominal 5\% level. The median accuracy of percentage time at tasks from the questionnaire was $91 \%$. Three tasks common to all trades included "break/ rest/cleanup", "manual material handle", and "work vehicle operation"; the reporting accuracy for these tasks ranged from $87 \%$ to $93 \%$ for all workers. By trade, the task reporting accuracy ranged from $78 \%$ to $96 \%$ for carpenters, and $53 \%$ to $100 \%$ for both electricians and sheet metal workers.

In addition to time spent at tasks, subjects were asked to report on tools, number of nearby workers, and work environment. The retrospective recall in these areas was no different than what had been recalled daily using the activity cards. Time spent using certain tools was slightly overreported on the questionnaire; five of nine tool categories were positively biased. Approximately four of nine tools were reported with an accuracy of $90 \%$ or better. The accuracy of reporting the number of workers was no greater than $76 \%$ and the accuracy for reporting the environment was no better than $62 \%$.

For all subjects, the reported use of hearing protection devices on the activity cards was $12.3 \%$ of the time; this percentage of time was significantly greater than the $8.5 \%$ time observed by research staff (Pearson $\chi^{2}, \mathrm{p}<0.05$, data not shown). The questionnaire did not ask for a percentage time using HPDs but rather "Do you always, sometimes, or occasionally wear HPDs when in a high noise area?". A "high noise area" was defined as having to raise one's voice to be heard by a co-worker within three feet of the subject. Three subjects reported never being in a "high noise area". Of 20 subjects that had been in a high noise area the use of HPDs as reported on the questionnaire was as follows: $25 \%$ always, $60 \%$ sometimes, and $15 \%$ occasionally wore hearing protection.

A comparison of noise estimates obtained from dosimetry, activity cards, and the questionnaire is shown in table 7 . For all subjects as well as the carpenter trade alone, there were differences between the noise estimate derived using dosimetry compared with both the activity card and questionnaire method, at the nominal 5\% significance level. However, noise estimates derived from the activity cards were strongly correlated with dosimetry measurements $\left(R^{2}=0.62\right.$, fig 1). Similarly, questionnaire based noise estimates were also strongly correlated with dosimetry measurements $\left(\mathrm{R}^{2}=0.59\right.$, fig 2$)$. Estimates from the activity cards and the questionnaire were on average $1.5 \mathrm{dBA}$ and $2.0 \mathrm{dBA}$, respectively, greater than the dosimetry estimate. There was no difference between the noise estimate derived from the activity cards as compared to the questionnaire (table 7 ) and these estimates were highly correlated $\left(R^{2}=0.91\right.$, fig 3$)$.

\section{DISCUSSION}

A task based exposure assessment strategy is appropriate for construction workers because of their dynamic work environment. However, when used in an epidemiology study, task based assessment relies on the ability of construction workers to accurately recall their tasks. This study was conducted to determine the accuracy of both daily self reports and six month recall by construction workers of tasks performed, tools used, work environment, number of nearby workers, and hearing protection usage. Validation of worker recall is key to exposure assessment in a prospective epidemiological study, such as that currently underway at the University of Washington in construction apprentices. The present study has shown that daily self reports by apprentice workers are substantially concordant with research observations for information such as task and environment, but only fairly concordant for reporting the number of nearby workers. The self reports were of sufficient quality for task and work environment that they could be used as a benchmark for validation of longer term recall. Six months after tasks were performed the accuracy for recalling time spent at given tasks ranged from $53 \%$ to $100 \%$. Average estimates of noise

Table 3 Variance components of dosimetry measurements

\begin{tabular}{|c|c|c|c|c|c|c|}
\hline Category & No. of subjects & No. of samples & k & ${ }_{\mathrm{B}} \sigma^{2}$ & $w \sigma^{2}$ & ${ }_{B} R_{95}$ \\
\hline All subjects & 25 & 130 & 5.2 & 4.2 & 3.2 & 16.4 \\
\hline Carpenter & 11 & 61 & 5.5 & 0.3 & 4.1 & 1.0 \\
\hline Electrician & 9 & 47 & 5.2 & 3.2 & 2.2 & 12.5 \\
\hline Other trades* & 5 & 22 & 4.4 & 5.3 & 1.8 & 20.8 \\
\hline
\end{tabular}

$k=$ average number of samples per worker.

$\mathrm{B} \sigma^{2}=$ variance between workers.

$\mathrm{W} \sigma^{2}=$ variance within workers.

${ }_{B} R_{95}=$ ratio of 97.5 th and 2.5 th centile of the between worker distribution (range of exposures).

${ }^{*}$ Other trades included labourer, sheet metal worker, sprinkler fitter, and operating engineer. 
Table 4 Correlation of daily activity cards and research observations

\begin{tabular}{|c|c|c|c|c|}
\hline \multirow{2}{*}{$\begin{array}{l}\text { Category } \\
\text { (no. of subjects) }\end{array}$} & \multirow{2}{*}{$\begin{array}{l}\text { No. of } \\
\text { minutes }\end{array}$} & \multicolumn{3}{|c|}{ Kappa statistic (SE) [\% agreement] } \\
\hline & & Task & Environment & No. of workers \\
\hline All subjects (17) & 4775 & $0.67(0.01)$ [69] & $0.70(0.01)[83]$ & $0.24(0.01)[58]$ \\
\hline Carpenters (8) & 2873 & $0.64(0.01)[72]$ & $0.71(0.02)[88]$ & $0.13(0.01)[49]$ \\
\hline Electricians (5) & 1231 & $0.64(0.01)$ [70] & $0.67(0.02)$ [78] & $0.41(0.02)$ [69] \\
\hline Other trades* $(4)$ & 671 & $0.51(0.01)[53]$ & $0.51(0.03)[71]$ & $0.49(0.03)[72]$ \\
\hline
\end{tabular}

exposure based on long term recall were no different from estimates derived from short term recall. While the activity card and questionnaire based noise estimates were respectively, on average 1.5 and $2.0 \mathrm{dBA}$ greater than dosimetry measurements, this difference was relatively consistent across the range of measurements with a high degree of correlation observed.

The ideal gold standard for validating long term recall would be to compare that recall to continuous researcher observations. In this study, a given subject was observed for approximately $11 \%$ per day for six of the 30 study days and this was not enough direct observation to validate the work history questionnaire. The daily activity cards, however, had been completed for approximately $88 \%$ time of the six week study. Because the daily activity cards were highly concordant with research observations and because they served as a complete record they were used to validate the work history questionnaire.

The results reported in this study regarding daily recall, long term recall, and exposure estimates are similar to the trends reported by Kalliokoski, in a study of chemical exposures in two rotogravure plants. ${ }^{26}$ In the present study, percentage time at task for two of 22 tasks were reported significantly differently $(\mathrm{p}<0.05)$ on the daily activity cards compared to the six month questionnaire. In Kalliokoski's study, end of shift questionnaires completed by workers were validated with researcher observation and time estimates for two of 34 tasks were significantly different ( $t$ test, $\mathrm{p}<0.05$ ). In addition, Kalliokoski's workers completed a questionnaire two months after the study in which they again estimated their average time distribution. Eight of the 34 tasks had statistically different average time fractions $(\mathrm{p}<0.05)$ reported at the two month recall compared to the daily recall. ${ }^{26}$ Kalliokoski reported that end-of-shift chemical exposure estimates were no different than estimates based on a two month retrospective questionnaire. ${ }^{26}$ Similarly, the noise estimates reported here were highly correlated with dosimetry measurements.

It is reasonable to think that completing daily activity cards could enhance subject recall. Thorough evaluation of this

Table 5 Reported percentage time at tasks

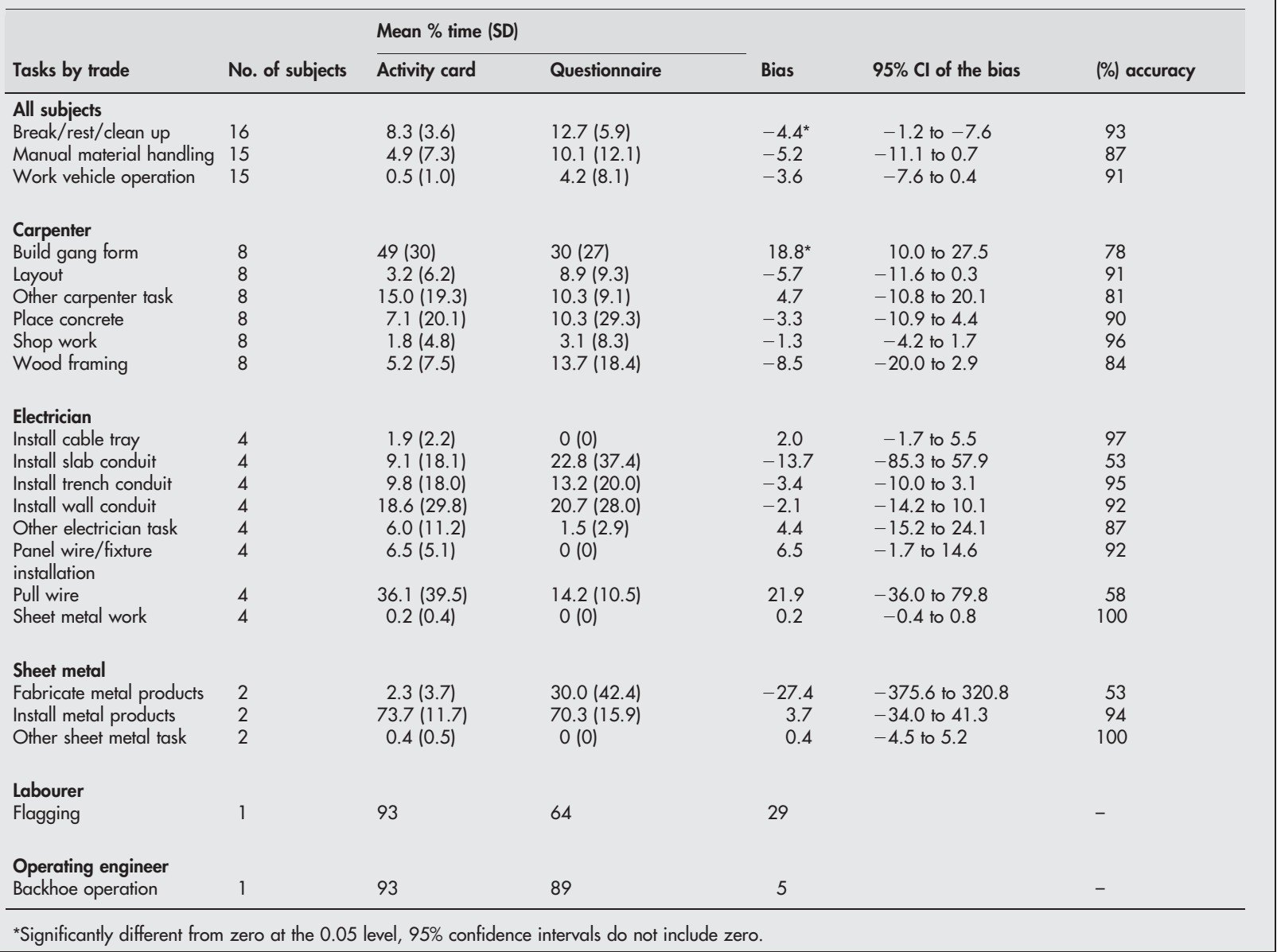


Table 6 Reported percentage time using tools and at environment parameters

\begin{tabular}{|c|c|c|c|c|c|c|}
\hline \multirow[b]{2}{*}{ All subjects } & \multirow[b]{2}{*}{ No. of subjects } & \multicolumn{2}{|c|}{ Mean \% time (SD) } & \multirow[b]{2}{*}{ Bias } & \multirow{2}{*}{$\begin{array}{l}95 \% \mathrm{Cl} \text { of } \\
\text { the bias }\end{array}$} & \multirow[b]{2}{*}{ (\%) accuracy } \\
\hline & & Activity card & Questionnaire & & & \\
\hline \multicolumn{7}{|l|}{ Tools } \\
\hline Chopsaw & 8 & $0.4(0.6)$ & $2.1(4.3)$ & -1.7 & -5.4 to 2.0 & 95 \\
\hline $\begin{array}{l}\text { Hammer/mallet/ } \\
\text { sledge/nailgun }\end{array}$ & 16 & $32.0(37.6)$ & $26.7(35.6)$ & 4.9 & -5.5 to 15.3 & 78 \\
\hline Hand power saw & 16 & 17.7 (21.5) & $16.3(22.6)$ & 1.4 & -6.9 to 9.6 & 83 \\
\hline Other hand power tool & 16 & $0.4(0.8)$ & $3.7(9.6)$ & -3.3 & -8.0 to 1.5 & 90 \\
\hline Other tool & 8 & $30.3(32.6)$ & $11.7(29.0)$ & 18.7 & -3.4 to 40.8 & 77 \\
\hline Powder actuated tool & 12 & $0.1(0.5)$ & 010 & 0.1 & -0.2 to 0.4 & 99 \\
\hline Rotohammer & 16 & 9.5 (14.5) & $15.3(21.7)$ & -5.7 & -12.4 to 1.0 & 85 \\
\hline Screwgun/drillmotor & 16 & $20.8(25.6)$ & $22.7(29.0)$ & -1.9 & -17.2 to 13.4 & 69 \\
\hline Stationary power tool & 16 & $0.5(1.3)$ & $1.1(2.7)$ & -0.6 & -2.1 to 1.0 & 97 \\
\hline \multicolumn{7}{|l|}{ No. of workers } \\
\hline 3 or less & 16 & $50.3(31.3)$ & $45.9(28.5)$ & 4.4 & -8.4 to 17.2 & 76 \\
\hline 4 or more & 16 & $41.7(30.4)$ & $54.1(28.5)$ & -12.3 & -25.6 to 0.9 & 72 \\
\hline \multicolumn{7}{|l|}{ Environment } \\
\hline Inside & 16 & $11.3(24.6)$ & $18.3(29.1)$ & -7.0 & -25.5 to 11.4 & 23 \\
\hline Partial enclosure & 16 & $34.1(40.1)$ & $33.4(33.0)$ & 0.7 & -19.4 to 20.7 & 62 \\
\hline Outside & 16 & $51.0(44.0)$ & $48.3(44.3)$ & 2.7 & -5.8 to 11.3 & 49 \\
\hline
\end{tabular}

effect would require comparison of workers who did, and did not fill out activity cards in relation to complete research observations. Although complete research observation was not feasible in this study, indirect evaluation of recall bias was evaluated by comparing exposure (noise dosimetry measurements) and tasks reported on the questionnaire (questionnaire based noise estimates) between subjects who did and did not fill out daily activity cards. No significant differences were observed between these two groups for carpenters or electricians in terms of either their measured exposure levels or their questionnaire recalled tasks. This provides some evidence that the recall accuracy was not substantially affected by completing the activity cards.

The daily reporting of tasks by both electricians and carpenters was substantially concordant with research observation. In a task based assessment of noise exposures of carpenters, electricians, ironworkers, and operating engineers, Neitzel et al compared worker self report of tasks with research observation, similar to the study described here. ${ }^{18}$ This comparable study reported a task associated correlation of kappa $=0.87$ for all workers, a somewhat higher correlation than reported here. Operating engineers have perhaps the smallest number of potential tasks compared to the other trades studied; they are typically assigned to one type of machinery for much of the day. Having a large percentage of subjects from the operating engineer trade could explain the higher correlation reported by Neitzel and colleagues. ${ }^{18}$ Van der Beek et al also validated self report of tasks in a study of musculoskeletal disorders in professional drivers and nurses. ${ }^{27}$ The subjects completed a diary over the course of one working day, with simultaneous researcher observation. Drivers recalled three of eight tasks with moderate or better agreement (kappa $\geqslant 0.41$ ) and nurses recalled just one of eight tasks with moderate or better agreement. The remaining tasks were recalled with fair or slight agreement (kappa $\leqslant 0.41)$.

In the current study, there was slightly more concordance for the reporting of work environment $(\mathrm{kappa}=0.70)$ than for task (kappa $=0.67$ ). Forty seven per cent of subjects consistently worked in and reported just one type of environment throughout the study period (that is, continuously driving a backhoe outside or doing electrical finish work inside) and this probably simplified their ability to recall the work environment.

Table 7 Comparison of noise estimates

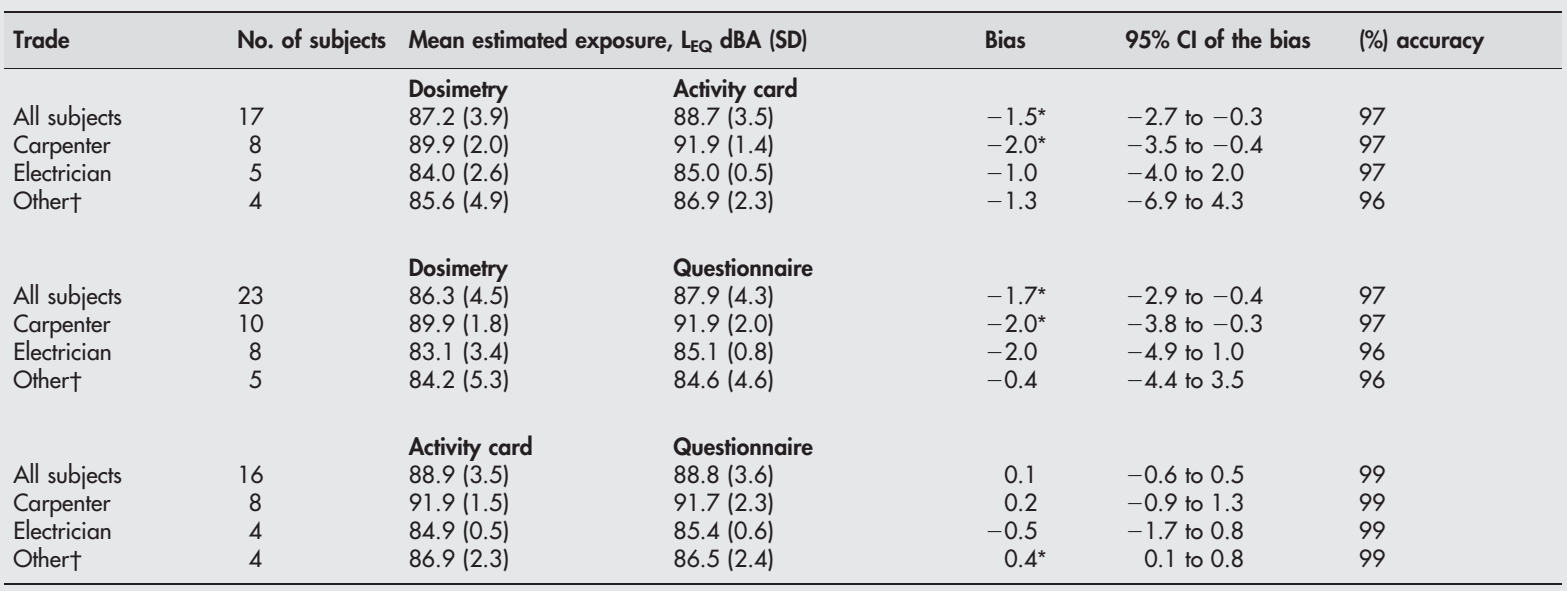

*Significantly different from zero at the 0.05 level, $95 \%$ confidence intervals do not include zero.

†Other trades included labourer, sheet metal worker, sprinkler fitter, and operating engineer. 


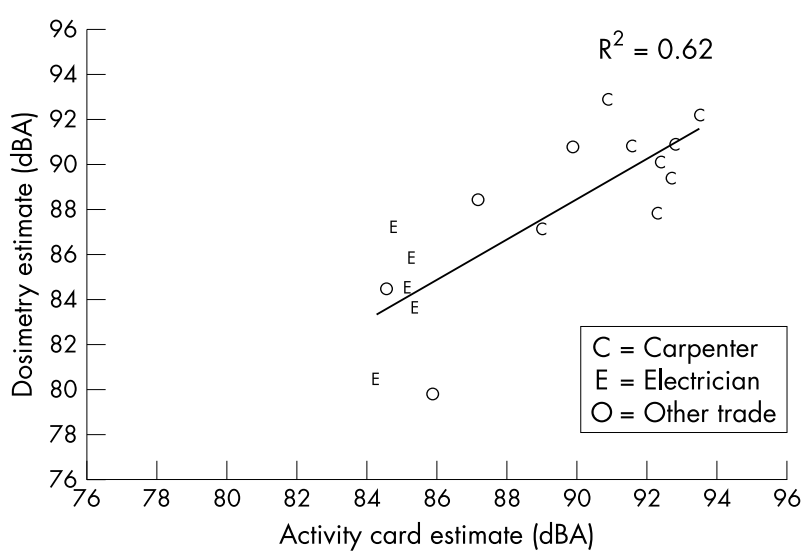

Figure 1 Correlation of activity card noise estimates and dosimetry measurements.

Detailed information such as the number of workers nearby did not correlate as well with research observations $($ kappa $=0.24)$. Because the subjects in this study were all apprentices, they were paired with one journeyman throughout the workday. The categories for choosing number of nearby workers were "3 or fewer" and " 4 or more". It was observed that the number of nearby workers typically fluctuated from three to five, which may have contributed to the relatively low agreement.

Very little information exists regarding construction workers' use of HPDs. On the activity cards, the percentage time that workers reported using hearing protection was $12.3 \%$, while research observations documented HPD use just 8.5\% of the time. Hearing protection (typically earplugs) was readily accessible to all workers at the construction sites visited in this study. The activity cards asked the workers to document their use of hearing protection on a daily basis, regardless of whether or not they were in a "high noise area". Lusk et al documented the self reported use of HPDs by operating engineers, plumber/pipefitters, and carpenters when in a high noise area as $49 \%, 32 \%$, and $18 \%$ time, respectively. ${ }^{28}$ The percentage of workers who consistently (95\% or more of the time) used HPDs ranged from 3\% in carpenters to $25 \%$ in operating engineers. ${ }^{28}$ The risk of noise induced hearing loss will not be reduced unless HPDs are consistently worn nearly $100 \%$ of overexposed time..$^{29}$ This study continues to suggest that HPDs are not worn frequently enough to afford adequate protection. Intervention strategies specific to construction workers for increasing the use of

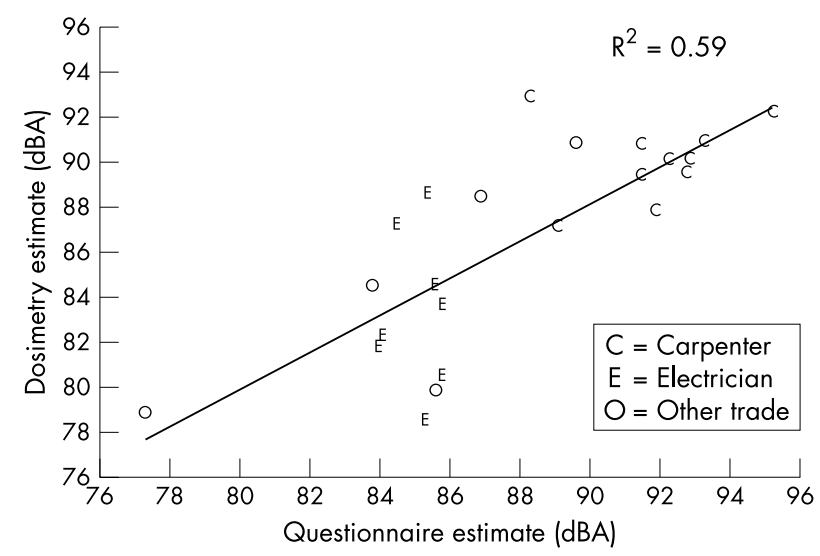

Figure 2 Correlation of questionnaire noise estimates and dosimetry measurements.

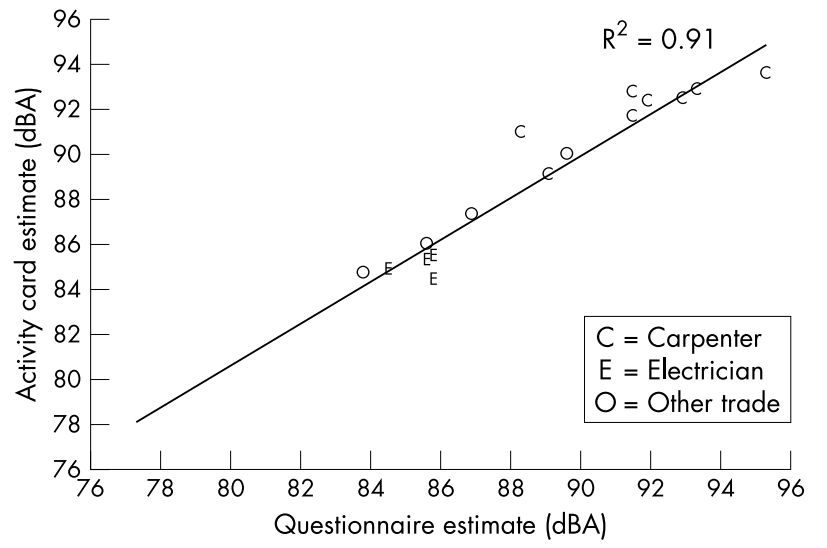

Figure 3 Correlation of questionnaire and activity card noise estimate.

HPDs have been suggested..$^{31}$ Reducing NIHL will undoubtedly require several strategies, including effective hearing conservation programmes and increased use of noise control technologies, as well as HPD use.

Estimates of noise exposure were derived from three different methods in this study. None of the methods was a complete assessment or "gold standard" measurement covering the entire six week study and each has advantages and disadvantages. The advantage of the dosimetry measurements is that they were direct measurements of noise and they took all environmental factors into account when calculating an individual's noise exposure. A disadvantage to dosimetry is that it was not possible to measure each subject every day. A given subject had dosimetry one day per week, or just $20 \%$ of the study period.

The advantage of having workers complete daily activity cards is that a complete, first hand record of activities can be obtained. Because the activity cards contain individual level information, the noise exposure estimate can distinguish between subjects with different activity patterns. The disadvantage of activity cards is that the reporting accuracy may be unknown. We conducted research observations to validate the activity cards; this was a highly labour intensive effort. Because the activity card information did correlate with research observations, the cards are a suitable benchmark for interpreting long term recall on the questionnaire. With research personnel regularly present on the worksites, dialogue on task definitions was ongoing and helped to ensure reporting accuracy of both researcher and worker.

The main advantage of the questionnaire is its efficiency in documenting a subject's activities for the six week study period. The use of a long term questionnaire for assessing exposure is a common tool used in epidemiological studies, but it can be difficult to validate. As the noise estimates derived from the questionnaire were no different from those derived from the activity cards, it can be concluded that the questionnaire alone was sufficient for estimating exposure. However, calculation of exposure from the questionnaire relied on both dosimetry and task specific noise levels (that is, activity cards) and could not have been calculated without either.

It is important to remember that the subjects in this study were from large commercial construction sites and therefore do not fully represent the entire construction industry. The subjects reported an average of 2.5 tasks per day (range 1-4 tasks). The number of tasks performed per day may fluctuate between workers on large commercial, small residential, or road construction sites. The construction workforce is very fluid; however, we targeted workers who expected to remain at their current location for at least six weeks. The fact that 
the subjects reported working at an average of only 1.8 sites throughout the six month recall period may in part reflect this targeted selection. Other construction workers may work at a greater number of different sites in a six month period, and the number of sites worked at could affect memory recall. This study had just a six month recall period. Longer recall periods could result in lower reporting accuracy.

\section{Conclusion}

The construction environment is a dynamic one, and exposure to various agents, including noise, may best be described using a task based exposure assessment strategy. This study shows that apprentice construction workers employed at large commercial construction sites can self report their tasks and work environment in substantial agreement with research observations. This finding is relevant to the many task based exposure assessment studies that are presently being conducted in the construction industry.

Construction workers can recall tasks with accuracy sufficient to support a reasonable assignment for exposure assessment in an epidemiological study. The percentage time at task reported six months after the initial study was, in general, no different from that reported on the daily activity cards for the same time period. Similarly, the resulting noise estimates derived from both the interview and the activity cards were not different from each other and were strongly correlated with dosimetry measurements.

\section{ACKNOWLEDGEMENTS}

This work was supported by Grant R01 OH03912 from the National Institute of Occupational Safety and Health (NIOSH) for the Centers of Disease Control and Prevention (CDC).

\section{Authors' affiliations}

C K Reeb-Whitaker, Washington Department of Labor and Industries, Safety and Health Assessment and Research for Prevention (SHARP) Program, PO Box 44330, Olympia, Washington 98504, USA N S Seixas, L Sheppard, R Neitzel, University of Washington, Department of Environmental Health, Seattle, Washington, USA

\section{REFERENCES}

1 Kenney GD, Ayer HE. Noise exposure and hearing levels in the sheet metal construction trade. Am Ind Hyg Assoc J 1975;36:626-32.

2 Pekkarinen J. Noise, impulse noise, and other physical factors: combined effects on hearing. Occup Med State Art Rev 1995; 10:545-59.

3 Schneider S, Susi P. An investigation of health hazards on a new construction project. CPWR Report OSHI-93. Washington, DC: Center to Protect Workers' Rights, 1993.

4 Sinclair JD, Haflidson WO. Construction noise in Ontario. Appl Occup Environ Hyg 1995; 10:457-60.
5 Legris $M$, Poulin P. Noise exposure profile among heavy equipment operators, associated laborers, and crane operators. Am Ind Hyg Assoc J 1998;59:774-8.

6 Environmental Protection Agency. Noise in America: the extent of the noise problem. Washington, DC: United States Environmental Protection Agency, 1981.

7 National Institute for Occupational Safety and Health (NIOSH). Criteria for a recommended standard: occupational noise exposure. DHHS (NIOSH) Publication No. 98-126. Cincinnati, OH: DHHS, 1998.

8 Sloan SP. Cardiovascular effects of noise. In: Noise and Health. New York, NY: Academy of Medicine, 1991:15-26.

9 Tomei F, Fantini S, Tomao E, et al. Hypertension and chronic exposure to noise. Arch Environ Health 2000;55:319-25

10 Kilburn KH, Warshaw RH, Hanscom B. Are hearing loss and balance dysfunction linked in construction workers? $\mathrm{Br} J$ Ind Med 1992;49:189-252.

11 Ringen K. National Conference on Ergonomics, Safety, and Health in Construction summary report. Am J Ind Med 1994;25:775-81.

12 Hetu $\mathbf{R}$. The hearing conservation paradigm and the experienced effects of occupational noise exposure. Canadian Acoustics 1994;22:3-19.

13 Susi P, Schneider S. Database needs for a task-based exposure assessment model for construction. Appl Occup Environ Hyg 1995; 10:394-8.

14 Greenspan CA, Moure-Eraso R, Wegman DH, et al. Occupational hygiene characterization of a highway construction project: a pilot study. Appl Occup Environ Hyg 1995; 10:50-8.

15 Blute NA, Woskie SR, Greenspan CA. Exposure characterization for highway construction. Part I: cut and cover tunnel finish stages. Appl Occup Environ Hyg 1999;31:310-18.

16 Susi P, Goldberg M Barnes P, et al. The use of a task-based exposure assessment model (T-BEAM) for assessment of metal fume exposures during welding and thermal cutting. Appl Occup Environ Hyg 2000;15:26-38.

17 Methner MM, McKernan JL, Dennison JL. Task-based exposure assessment of hazards associated with new residential construction. Appl Occup Environ Hyg 2000;15:811-19.

18 Neitzel R, Seixas N, Camp J, et al. An assessment of occupational noise exposures in four construction trades. Am Ind Hyg Assoc J 1999;60:807-17.

19 Goldberg M, Levin SM, Doucette JT, et al. A task-based approach to assessing lead exposure among iron workers engaged in bridge rehabilitation. Am J Ind Med 1997;31:310-18.

20 Bourbannais R, Meyer F, Theriault G. Validity of self reported work history. Br J Ind Med 1988;45:29-32.

21 Birdsong WH, Lash AA, Thayer S, et al. The validity of study group assignments based on occupational histories obtained from questionnaires. $J$ Occup Med 1992;34:940-5.

22 Baumgarten M, Siemiatycki J, Gibbs GW. Validity of work histories obtained by interview for epidemiology purposes. Am J Epidemiol 1983:118:583-91.

23 Boleii JSM, Buringh E, Heederik D, et al. Occupational hygiene of chemical and biological agents. Elsevier, 1995:106-9.

24 Landis JR, Koch GG. The measurement of observer agreement for categorical data. Biometrics 1977;33:159-74.

25 Hornung RW. Statistical evaluation of exposure assessment strategies. Appl Occup Environ Hyg 1991:6:516-20.

26 Kalliokoski P. Estimating long-term exposure levels in process-type industries using production rates. Am Ind Hyg Assoc J 1990;51:310-12.

27 Van der Beek AJ, Braam ITJ, Douwes $M$, et al. Validity of diary estimating exposure to tasks, activities, and postures of the trunk. Int Arch Occup Environ Health 1994:66:173-8.

28 Lusk SL, Kerr MJ, Kauffman SA. Use of hearing protection and perceptions of noise exposure and hearing loss among construction workers. Am Ind Hyg Assoc J 1998;59:466-70

29 Else $\mathbf{D}$. A note on the protection afforded by hearing protectors -implications of the energy principle. Ann Occup Hyg 1973;16:81-3.

30 Dear TA. Updating damage risk criteria to include performance under workplace noise regulations. J Occup Hearing Loss 1998;1:61-6.

31 Lusk SL, Kerr MJ, Ronis DL, et al. Applying the health promotion model to development of a worksite intervention. Am J Health Promot 1999;13:219-27. 